Article

\title{
Development of an Indoor Environmental Quality Assessment Tool for the Rating of Offices in Real Working Conditions
}

\author{
Anna Devitofrancesco* * , Lorenzo Belussi ${ }^{(}$, Italo Meroni and Fabio Scamoni \\ Construction Technologies Institute of the National Research Council of Italy (ITC-CNR), via Lombardia 49, \\ San Giuliano Milanese, 20098 Milan, Italy; belussi@itc.cnr.it (L.B.); meroni@itc.cnr.it (I.M.); \\ scamoni@itc.cnr.it (F.S.) \\ * Correspondence: anna.devitofrancesco@itc.cnr.it; Tel.: +39-02-9806310
}

Received: 22 February 2019; Accepted: 15 March 2019; Published: 19 March 2019

check for updates

\begin{abstract}
The Indoor Environmental Quality (IEQ) refers to the quality of indoor spaces in relation to the health and well-being of users. IEQ is a holistic concept considering various components of the overall indoor comfort: thermo-hygrometric, lighting, air quality and acoustics. Each component is described through specific performance indicators and benchmarks. The quality of the built environment is assessed at different stages from design to operational phase. The scientific literature reports several case studies related to the assessment of the individual components of the IEQ Tools aimed at the evaluation of the overall IEQ. The paper proposes an assessment tool based on the SB Method (Sustainable Building Method) and the Multi Criteria Analysis for the evaluation of IEQ during the operational phase of a building. Each component of IEQ is analysed through objective indicators and calculation methods. The tool provides two main outcomes: a global score expressing the overall performance of the building from the IEQ perspective; quantitative evaluations of all indoor comfort components through monitoring and measurement of the environmental variables. The above contributes to select intervention areas to optimize indoor design and to identify technologies aimed at ensuring the best IEQ levels for users at the operational stage. The system was applied to an open-plan working space of an office building. Monitoring activities and measurements are carried out to detect the indoor and outdoor variables affecting the IEQ. All aspects of IEQ were analysed and quantified so to evaluate the overall performance of the building and provide data to improve the working conditions.
\end{abstract}

Keywords: indoor environmental quality; SB method; multi criteria analysis; monitoring and measurement; office building; real working conditions

\section{Introduction}

The issue of sustainability has affected the scientific community and international governments for decades. The concept of sustainable development, defined as the "development that meets the needs of the present without compromising the ability of future generations to meet their own needs" [1] is a mantra repeated over and over again with different degrees of intensity and awareness in all areas related to human activities. In recent years, this paradigm has become particularly relevant within the building sector and the built environment [2]. It is an acknowledged fact that buildings account for more than $40 \%$ of the global energy consumption and more than a third of greenhouse gas emissions [3]. The building sector reveals a high potential in terms of reducing energy consumption and climate-changing emissions [4]. Furthermore, increasing attention is being paid to the Indoor Environmental Quality (IEQ) aimed at designing a comfortable indoor environment with a specific 
focus on users' well-being [5]. Researches on this topic cover a large number of issues, considering different aspects of the IEQ [6,7], and are carried out in buildings with different intended uses [8] and involving different categories of end users, taking into account their real response to environmental stimuli [9]. Some researches face the problem from a technological point of view, developing methods and tools aimed at managing and controlling the environmental variables in order to guarantee the best indoor conditions and energy savings $[10,11]$. Other researches aim at defining a classification of buildings from the point of view of indoor comfort [12].

Many building environmental assessment methods have been developed since the 1990s, allowing the overall assessment of the building performance based on the aggregation of results in a single evaluation or sustainability score [13]. The assessment tools differ according to the adopted categories [14] and the weighting methods [15]. In general, the different assessment systems consist of a common core of environmental categories: Energy, Water Efficiency, Waste, Materials and Resources, Site Sustainability, Environmental Loading, Transport, Indoor Environmental Quality; other categories are specific for the system itself [16]. The main difference between the assessment methods is related to the weighting system, which consists in assigning a variable weight to each category and to the scoring system in which the individual scores, weighted or not, are added together to obtain the final evaluation [17]. The assessment methods can be applied at different levels, from buildings [18] to neighborhoods [19] and urban areas [20], and at different phases of the construction process, from the design to the construction and use phases [21].

Studies and researches are focused on the assessment of the performance of buildings in the operating phase and the identification of specific indicators for their evaluation [22,23]. Several studies assess the performance of buildings certified by the most popular rating and labeling systems. In Reference [24] the authors compare the performance of two office buildings, one of which certified as "Very Good" by BREEAM Offices 2008. The analysis shows a better behavior of the certified building in terms of both energy consumption and users' satisfaction. Similar results are obtained by References [25] and [26] on a residential hall and a commercial buildings certified LEED Platinum and Gold, respectively. Baird and Field [27] analyse the IEQ of many buildings worldwide, characterized by low energy design or rated as highly sustainable, highlighting that the IEQ is an important component of the operational phase of a building affecting the health, productivity and well-being of occupants, as well as lifecycle costs and energy consumption [28]. Systems for assessing the environmental sustainability of buildings provide specific tools for analysing the impact of the use phase of a building: BREEAM In-Use, LEED for Building Operation and Maintenance (O+M), DGNB (German Sustainable Building Council) tool for Office and Administrative Buildings In-Use, HQE (Haute Qualité Environmentale) for buildings in use.

In Italy, one of the most important tools for the assessment of the environmental sustainability of constructions is the "Protocollo ITACA" developed by the Institute for the Transparency of Contracts and Environmental Sustainability (ITACA). This tool is based on the Sustainable Building (SB) Method [29], a multicriteria methodology defined by the "Green Building Challenge" international research project. Such project, which has been managed by iiSBE (International Initiative for Sustainable Built Environment) since 2002, aims at quantifying, through a performance score, the level of sustainability of a building compared to the typical construction practice of a reference geographical region, defined as a benchmark.

The assessment tools based on the SB Method analyse the sustainability level of a building through the evaluation of a series of performance indicators. The methods provide a quality score for each indicator and an overall final score which summarizes the building's global sustainability performance. The ITACA Protocol consists of a set of performance criteria organized in categories covering five thematic areas relating to the following construction sustainability issues: impact on site, energy, water and materials consumption, greenhouse gas emissions, waste, IEQ and service quality. The building evaluation range is composed of 7 levels, from value -1 (performance below the standard) to 5 (advanced performance), where value 0 corresponds to the "current practice", i.e., 
the minimum acceptable performance defined by law. Value 3 corresponds to the "best practice", which represents a significant improvement compared over the existing regulations and common practice [30]. The ITACA Protocol is widely used in Italy and the methodology has become the core of specific technical standards. The Protocol has different purposes in relation to its different uses: this tool can support design for professionals, provide control and guidance to Public Administrations, support the choices of for end users and ensure an investment enhancement for financial operators. To date, ITACA Protocol can carry out evaluations during the design phase and the "as built" phase; no tool among ITACA Protocols is suitable for application during the operational phase [31].

The article describes this tool based on the SB Method that can assess IEQ in offices in real working conditions. The main characteristic of the assessment tool is its ability to quantify the performance of the building or of a part of it and to select intervention areas to optimize indoor design in order to guarantee the best IEQ for users at the operational stage.

\section{Materials and Methods}

The assessment tool allows the evaluation of IEQ levels of tertiary buildings in real working conditions according to the guidelines of the SB Method. The indices considered in the tool are: indoor thermal comfort, indoor air quality, visual comfort, acoustic quality and electromagnetic pollution. The tool aims at validating the compliance with technical standards and regulatory requirements concerning comfort in real working conditions and at identifying the overall level of environmental quality through a score in a range from -1 up to 5, in compliance with the SB Method. The system includes objective indicators and standard calculation methods in order to guarantee the repeatability in different built environments and contexts.

The process requires specific monitoring and measurement activities of the main environmental variables. The tool assesses the real performance of the indoor environment. The development process of the tool can be summarized in the following steps: (i) "selection of criteria"; (ii) "benchmarking" and (iii) "weighting".

\subsection{Selection of Criteria}

The criteria for the development of the tool have been selected in accordance with the following common rules [32]: (i) relevance of IEQ aspects analysing the current state-of-the-art, (ii) life cycle phase, (iii) typology of indoor environment (i.e., intended use, layout, etc.), (iv) possibility of intervention to modify the specific phenomenon represented by the indicator.

Reference technical standards and international literature review on IEQ aspects have been carefully analysed. Standard EN 15251 [33] identifies indicators and environmental parameters to be used by monitoring and displaying the indoor environment in existing buildings with human occupancy. It provides the references about specific technical standard to be used for the evaluation of each IEQ aspect. In Table 1 the reference standards are summarized for each IEQ aspect.

Table 1. Reference standards and decrees for the assessment of comfort categories.

\begin{tabular}{ll}
\hline \multicolumn{1}{c}{ Categories } & \multicolumn{1}{c}{ Reference Standard } \\
\hline Indoor air quality & EN 13779 [34] \\
Indoor thermal comfort & ISO 7730 [35] \\
Visual comfort & EN 12464-1 [36], EN 15193 [37], \\
Acoustic quality & EN ISO 3382-2 [38], EN ISO 3382-3 [39], EN ISO 9921 [40], IEC 60268-16 [41] \\
Electromagnetic pollution & Legislative Decree 81, Decree of the President of the Council of Ministers \\
& 8 July 2003 [42] \\
\hline
\end{tabular}

Moreover, some of the main voluntary assessment tools adopted by approved bodies for the certification of building sustainability (i.e., the English BREEAM, the American LEED, the international SBTool, City, Country) have been analysed highlighting their most relevant elements. Each certification 
system has a thematic area that evaluates conditions of well-being in indoor environments and contains indicators referring to comfort categories such as thermal, acoustic, visual and air quality conditions.

Secondly, the choice of specific indicators reflects the life cycle phase selected for assessment. According to the main goal of the tool, i.e., the evaluation of indoor environment in real working conditions, only indicators that considered monitored data and parameters during the operational phase were selected.

Thirdly, the intended use of building is crucial in relation to the indicators. The tool considers a particular layout of office buildings that is currently one of the most widely used in the design choices of companies and architects, i.e., the open space. In order to better consider the functional layout of this space, the criteria were chosen and built to evaluate the environment in relation to the characteristics that a working activity in this kind of spaces entails. Some considerations can be made for each criterion concerning thermal, visual and acoustic quality, i.e., those more influenced by the user's subjectivity. Thermal comfort is evaluated considering both the global and local index. The former considers the individuals as a whole while the latter considers discomfort conditions in specific parts of the body. Thermal comfort is analysed by taking into account sedentary activities (sitting at a desk) and business clothing for both women and men. For the local indices, the vertical air temperature difference and air draught are considered. The main activity of occupants takes place at the desk considered as the reference of the visual task. Since the tool is to be applied first to open-plan offices, indicators that can characterize the acoustic quality of this type of environment are considered e.g., the reverberation and the decrease in work performance.

\subsection{Benchmarking}

In the "Benchmarking" activity, reference performances are defined for comparison with the performance of the indoor environment under analysis. They represent the standard performance level and are used to score the performances in a numerical scale. Benchmarks were developed considering legal standards and laws at national or international level. Benchmarks are based either on: i) the reference standards and laws in force in Italy or, in the absence of regulations and laws in force in Italy, on ii) standards in force in other countries. In this way, the assessment of the IEQ of open-plan offices is framed in the geographical, political and climate context in which it takes place. This kind of benchmarking makes the IEQ tool easily replicable in any office building located in Italy. The benchmark scale includes four scores corresponding to different reference performance levels of sustainability, as summarized in Table 2.

Table 2. Score and Performance scale.

\begin{tabular}{cl}
\hline Score & \multicolumn{1}{c}{ Performance } \\
\hline-1 & Represents a performance below the standard required \\
0 & Represents the minimum acceptable performance defined by laws or regulations in force \\
3 & Represents the best performance compared to regulations in force \\
5 & Represents a higher performance compared to the current best practice (excellence) \\
\hline
\end{tabular}

The benchmarks are defined according to the SB Method as Level 0 and Level 5. Level 0 is usually the minimum requirement laid down in laws or standards and corresponds to the value of Category III of EN 15251. Category III describes a moderately acceptable level of expectation and may be used for existing buildings. Level 3 represents best practice or best requirement. The value has been calculated as the highest performance of indoor environments or it is the best requirement laid down in laws or standards corresponding to Category II of standards that is a normal level of expectation, but used for performance of new buildings and renovations. Level 5 corresponds to a considerably advanced performance with reference to the current best practice, which can be experimental and may require a big initial economic investment. If the matter is covered by regulations and the limit values established by the law are particularly severe, or have to be applied within a relatively long period, Level 5 of 
the benchmark scale is assigned to these values. Furthermore, in the IEQ tool Level 5 coincides with Category I which provides for a high level of expectation and is recommended for spaces occupied by very sensitive and fragile persons.

\subsection{Weighting}

"Weighting" is the assignment of percent weights to all levels of the assessment system (Thematic areas, Categories and Indicators). The weighting method of this system is based on the guideline of the SB Method.

Weights are assigned according to the relative importance of each thematic area, category and indicator with respect to some goals and criteria chosen by the developers of the system. Therefore, the importance (weight) of the thematic areas and categories reflects the policy making context and some specific characteristics of the indoor environment assessed (e.g., a higher weight is assigned to "thermal comfort" categories because of its great relevance, especially for indoor environments located in cold climate areas (northern Italy)).

Instead, the weights of single indicators instead reflect "technical choices", that is "votes" assigned by experts based on three criteria: (i) "importance" of the indicator with reference to indoor environmental quality concepts and issues; (ii) "governability" which reflects the possibility for the owner of the building or the manager or the customer to modify the specific phenomenon represented by the indicator; (iii) "stability" namely the expected duration of the impact on sustainability after the interventions.

The weighted average of scores provides the final overall score as follows:

$$
S=\sum\left(s_{i} \cdot w_{i} \cdot w_{c}\right)
$$

where

$s_{i} \quad$ is the score of $i$ indicator

$w_{i} \quad$ is the weight of $i$ indicator within its category

$w_{c}$ is the weight of $i$ indicator category within its thematic area.

\subsection{Structure}

The IEQ tool is divided into three assessment levels in compliance with the SB Method. The most general level is "Thematic areas" represented by a single area which coincides with the "Indoor Environmental Quality". IEQ area includes 5 "Categories" which represent the second level of the assessment and are related to the most important IEQ aspects considered.

Each category is divided into several "Criteria"(third level) which provide the specific level of sustainability performance based on which the indoor spaces are assessed (Table 3). They are represented by an indicator that is the parameter to be measured and calculated. The criteria were defined according to standard EN 15251, except for the category "Electromagnetic pollution" required by the Italian Legislative Decree No. 81 on the safeguard of health and safety at the workplace. The "Indoor Air Quality" criterion has been actually investigated through the analysis of $\mathrm{CO}_{2}$ concentration. Future developments of the tool will provide the possibility to quantify further indoor environmental pollutants (total volatile organic compounds, other particulate matters, etc.) that can affect users' health [43].

The overall level of sustainability is obtained by aggregating the performances of individual indicators in relation to their weights and to the weight of the category in which they are included. 
Table 3. Criteria and indicators of the IEQ tool.

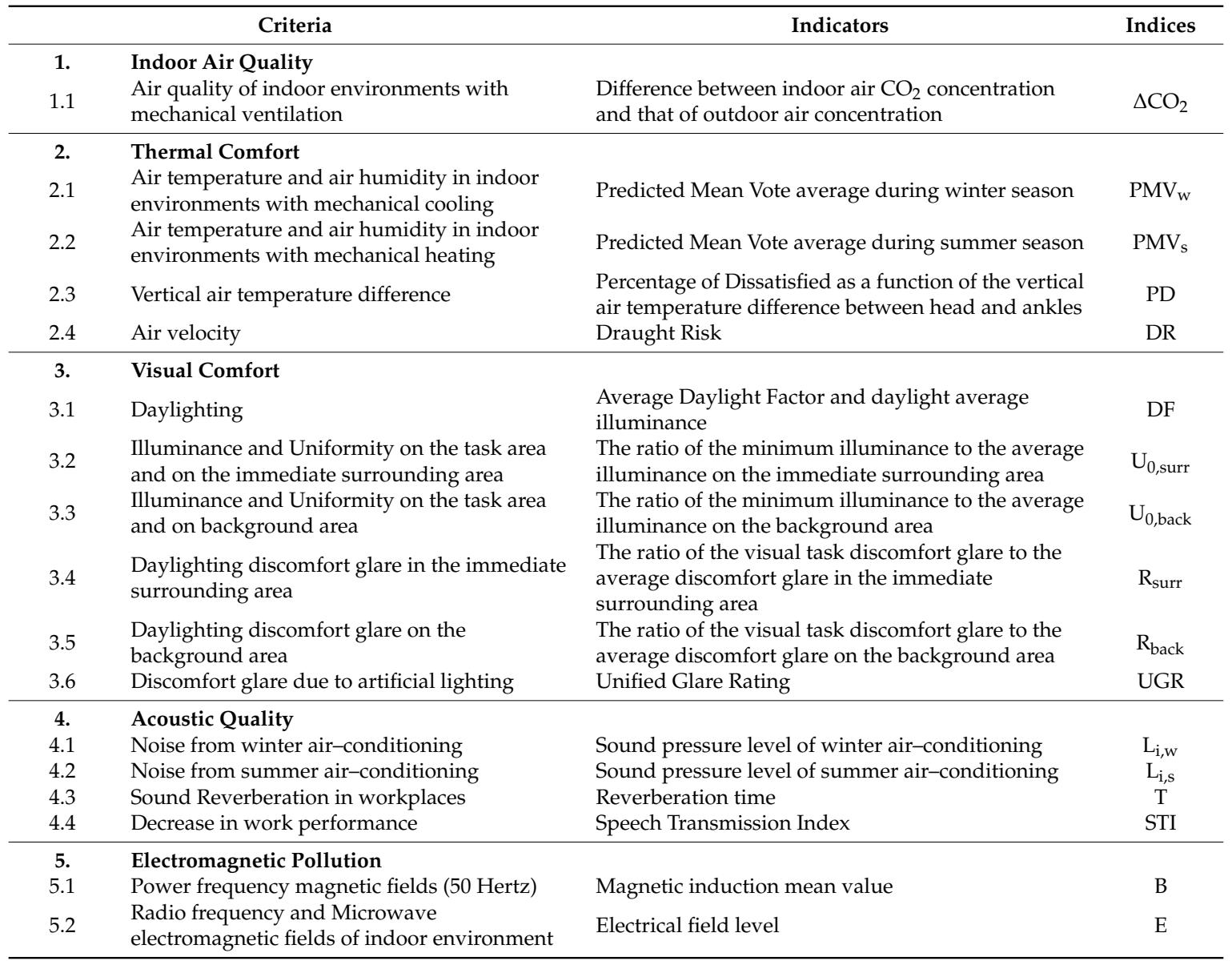

The indicator value is calculated with two methods: with the former, the indicator coincides with the average of values of the indicators calculated for each considered workstation, while through the latter, the indicator corresponds to the worst value calculated among the workstations considered.

Specific sheets are used to describe each individual criterion. These sheets are implemented in an easy-to-use spreadsheet that allows to calculate the relevant indicators.

The structure of the sheet is the same for all criteria and includes the following information:

a. Name, code and position of the indicator in the general framework (i.e., category it belongs to);

b. Objective: target of sustainability for which the indicator is relevant;

c. Weight: weight criterion in the category and weight criterion in the tool as a whole;

d. Performance Indicator: the value used to assess the level of performance of the criterion; it can be either quantitative or qualitative (in this case it is described as a 'scenario');

e. Unit of measurement;

f. Benchmark scale: indicator reference values;

g. Indicator value; calculated value of urban area evaluated;

h. Score: performance score of the indicator in relation to the indicator value and the related benchmark;

i. Notes: clarifications about the calculation method of indicator value and/or about the measurement method of the parameter.

Figure 1 shows an example of a criterion sheet filled in with the value of the indicator measured during the application of the tool to the case study and the value of the score relating to the specific comfort conditions. The authors can disclose all criteria sheets for consultation. 


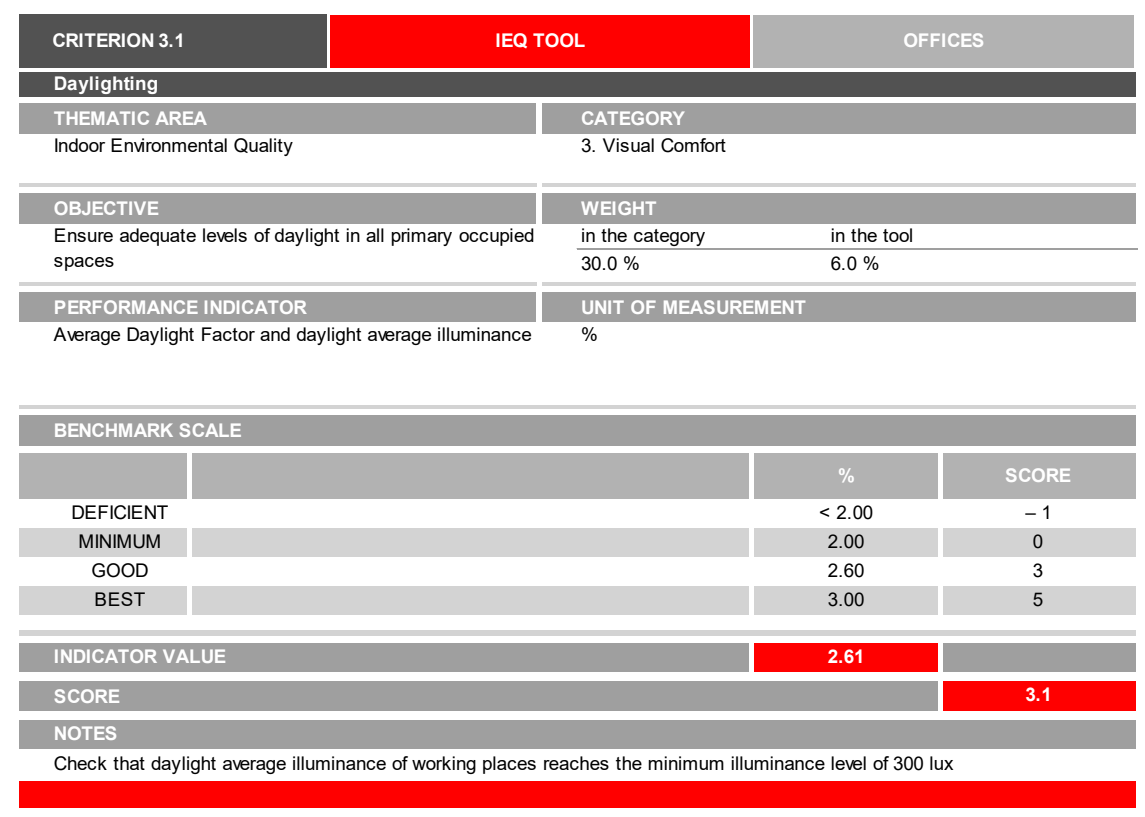

Figure 1. "Daylighting" criterion sheet.

\section{Case Study}

The IEQ tool was tested on a recently refurbished multi-storey office whose existing indoor spaces have been transformed into efficient open spaces. The building consists of five floors above ground. The tests were conducted in the offices located on the second floor of the building. The internal layout consists of open-spaces punctuated with enclosed spaces used as meeting rooms in the central part.

A monitoring campaign was organized to evaluate the performance of the building, providing for the installation of fixed sensors and punctual surveys for the detection of the environmental variables influencing the IEQ. The hardware was widely located on the work surface in points considered strategic for the evaluation. The experimental campaign was conducted in two seasons, winter and summer, with a two-week survey period. The punctual surveys were conducted on specific days within those periods. Figure 2 shows the location of measurements performed indoors.

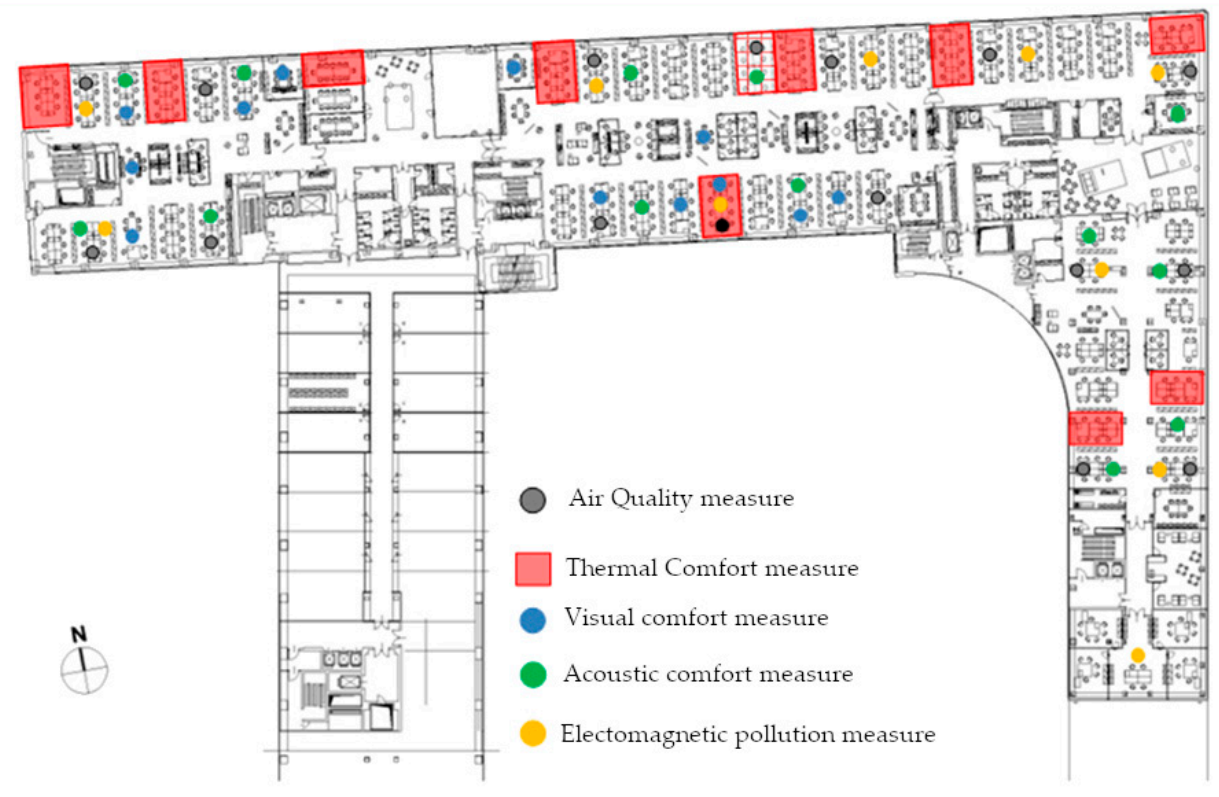

Figure 2. Location of the fixed sensors and punctual surveys. 
Table 4 shows the frequency of the monitoring campaign for the assessment of each criterion. The choice often depends on the considered variables. As some of them require an extended monitoring period (typically one week), others require an immediate and punctual detection.

Table 4. Frequency of monitoring for each criterion.

\begin{tabular}{|c|c|c|c|c|c|c|c|c|c|c|c|c|c|c|c|c|c|}
\hline \multirow[t]{2}{*}{ Period } & \multicolumn{17}{|c|}{ Criteria } \\
\hline & 1.1 & 2.1 & 2.2 & 2.3 & 2.4 & 3.1 & 3.2 & 3.3 & 3.4 & 3.5 & 3.6 & 4.1 & 4.2 & 4.3 & 4.4 & 5.1 & 5.2 \\
\hline Winter weeks & - & $\bullet$ & - & $\bullet$ & $\bullet$ & - & - & - & - & - & - & - & - & - & - & - & - \\
\hline Summer weeks & - & - & $\bullet$ & $\bullet$ & $\bullet$ & - & - & - & - & - & - & - & - & - & - & - & - \\
\hline Punctual surveys & $\bullet *$ & - & - & - & - & $\bullet$ & $\bullet$ & $\bullet$ & $\bullet$ & $\bullet$ & $\bullet$ & $\bullet *$ & •** & $\bullet$ & $\bullet$ & $\bullet$ & $\bullet$ \\
\hline
\end{tabular}

${ }^{*}$ Winter day. ${ }^{* *}$ Summer day.

A fixed external weather station was placed on the roof of the building and connected with a multichannel data logger, for the detection of external environmental variables:

- External air temperature and relative humidity;

- Global radiation (diffuse and direct);

- Wind velocity and direction;

- $\quad$ Direct and diffuse illuminance.

Table 5 shows the technical characteristics of the chosen sensors.

Table 5. Technical features of the sensors of the meteorological station.

\begin{tabular}{ccl}
\hline Variable & \multicolumn{1}{c}{ Sensor } & \multicolumn{1}{c}{ Technical Characteristics } \\
\hline Air temperature & Thermo-hygrometric sensor & $\begin{array}{l}\text { Measuring range }-40 \text { to } 80{ }^{\circ} \mathrm{C} \\
\text { Accuracy } \pm 0.1{ }^{\circ} \mathrm{C}\end{array}$ \\
Relative Humidity & Thermo-hygrometric sensor & $\begin{array}{l}\text { Measuring range } 0 \%-100 \% \\
\text { Accuracy } \pm<1 \%\end{array}$ \\
Global radiation & Peasuring range 0 to $2000 \mathrm{~W} / \mathrm{m}^{2}$ \\
Wind velocity and direction & Triaxial sonic anemometer & $\begin{array}{l}\text { Accuracy }< \pm 2 \% \\
\text { Measuring range } 0 \text { to } 60 \mathrm{~m} / \mathrm{s}\end{array}$ \\
Direct and diffuse illuminance & & $\begin{array}{l}\text { Accuraring range } 0 \text { to } 200 \mathrm{klux} \\
\text { Accuracy }<8 \%\end{array}$ \\
\hline
\end{tabular}

Figure 3 shows the external meteorological station on the top of the building.

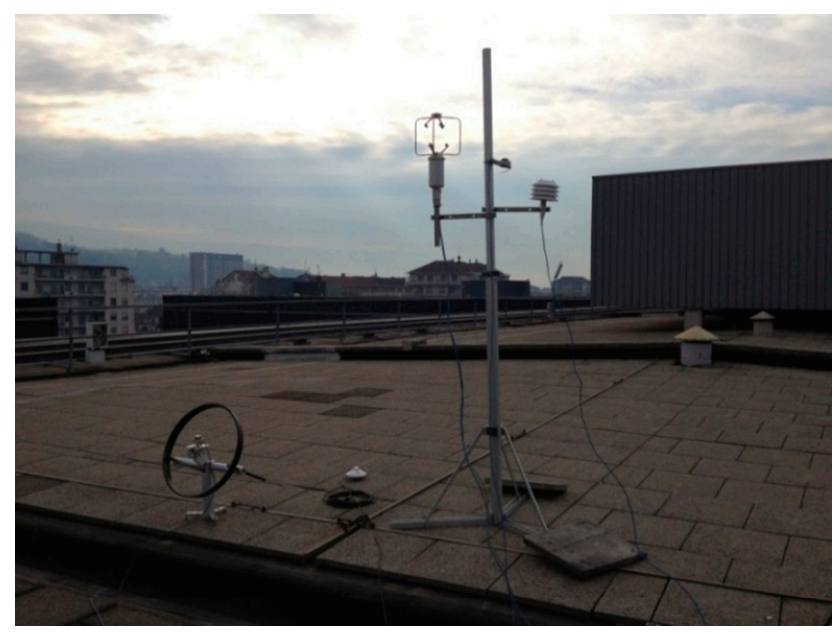

Figure 3. External meteorological station. 
The indoor air quality was assessed as a function of the $\mathrm{CO}_{2}$ concentration with respect to the external environmental conditions. The measurements were made using a $\mathrm{CO}_{2}$ analyser in the most representative environments during the hours considered the most critical for this type of analysis. Table 6 illustrates the technical characteristics of the sensors.

Table 6. Technical features of the sensors for the measuring of lighting variables.

\begin{tabular}{ccc}
\hline Variable & Sensor & Technical Characteristics \\
\hline $\mathrm{CO}_{2}$ concentration & $\mathrm{CO}_{2}$ analyser & $\begin{array}{c}\text { Measuring range } 0 \text { to } 9999 \mathrm{ppm} \\
\text { Accuracy } \pm 75 \mathrm{ppm}\end{array}$ \\
\hline
\end{tabular}

Twelve fixed stations were installed for the detection of the internal variables affecting the thermal comfort consisting of the following sensors:

- $\quad$ Resistance thermometers pt 100 (RTD);

- Indoor humidity sensor;

- Black-globe thermometer for the detection of the mean radiant temperature;

- Omnidirectional hot-wire anemometer.

The air temperature sensors were placed at three different heights: at $50 \mathrm{~cm}$ from the floor, at $50 \mathrm{~cm}$ from the ceiling and at $150 \mathrm{~cm}$ from the ground, to evaluate the vertical distribution of the temperature, they may cause discomfort. Table 7 illustrates the technical characteristics of the sensors.

Table 7. Technical features of the sensors for the measuring of thermal variables.

\begin{tabular}{|c|c|c|}
\hline Variable & Sensor & Technical Characteristics \\
\hline & \multirow{4}{*}{ Pt100 RTD and electrical capacity } & Measuring range -40 to $+80^{\circ} \mathrm{C}$ \\
\hline Air temperature & & Accuracy $\pm 0.1^{\circ} \mathrm{C}$ \\
\hline Relative humidity & & Measuring range $0 \%-100 \%$ \\
\hline кеганіve numiaity & & Accuracy $\pm 1 \%$ \\
\hline Mean air temperature & Globetermometer & $\begin{array}{l}\text { Measuring range }-40 \text { to }+60^{\circ} \mathrm{C} \\
\text { Accuracy } \pm 0.1^{\circ} \mathrm{C}\end{array}$ \\
\hline Air velocity & Hot wire anemometer & $\begin{array}{l}\text { Measuring range } 0 \text { to } 5 \mathrm{~m} / \mathrm{s} \\
\text { Accuracy } \pm 0.1 \mathrm{~m} / \mathrm{s}\end{array}$ \\
\hline
\end{tabular}

Figure 4 shows an internal station for the detection of the variables that affect the indoor thermal comfort.

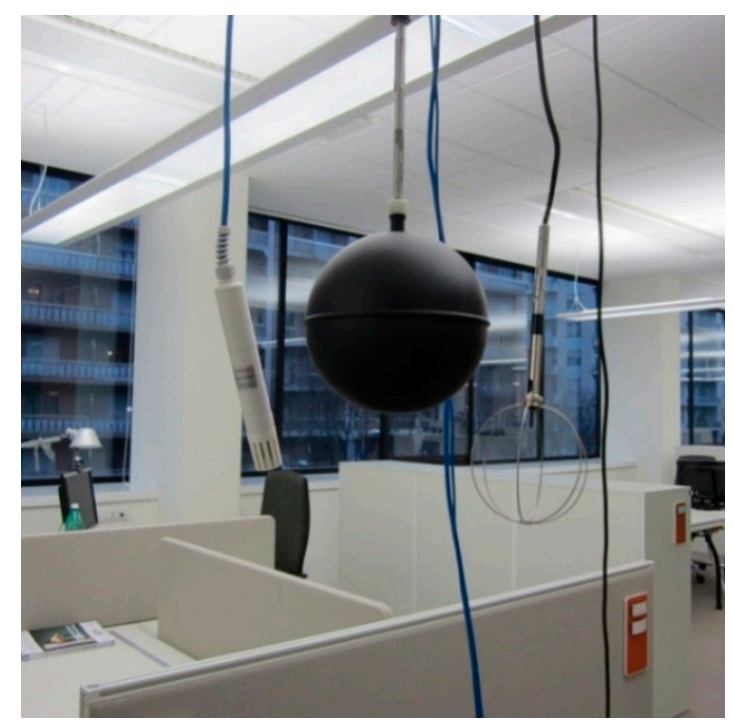

Figure 4. Internal station for the measurements of the thermal comfort variables. 
Visual comfort was assessed both with a station with fixed sensors, luxmeters, for the evaluation of the level of illuminance reached during working hours and with punctual surveys for the evaluation of the mean illuminance level, uniformity of illuminance and glare from natural and artificial light at different times of the day, using portable luxmeters and luminance meters. Table 8 shows the technical characteristics of the used sensors used.

Table 8. Features of the sensors for the measuring of lighting variables.

\begin{tabular}{|c|c|c|}
\hline Variable & Sensor & Technical Characteristics \\
\hline $\begin{array}{l}\text { Internal } \\
\text { illuminance }\end{array}$ & Luxmeter & $\begin{array}{l}\text { Measuring range } 0 \text { to } 2 \text { klux } \\
\text { Accuracy }<8 \%\end{array}$ \\
\hline Punctual luminance & Luminance meter & $\begin{array}{l}\text { Measuring range } 0.01 \text { to } 999.900 \mathrm{~cd} / \mathrm{m}^{2} \\
\text { Accuracy } \pm 2 \%\end{array}$ \\
\hline
\end{tabular}

The noise from the air-conditioning equipment was measured at the workstations while the reverberation time was measured in places with different furniture and false ceiling. Finally, for the assessment of the work performance, measurements were carried out along a line which crosses over the chosen workstations, with no people and with the air-conditioning on.

The equipment used for the assessment of the acoustic requirements is the following:

- $\quad$ Sound Level Meter;

- Prepolarized Free-Field $\frac{1}{2}{ }^{\prime \prime}$ microphones;

- Omnidirectional sound source;

- $\quad$ Sound level calibrator.

Figure 5 shows the equipment and their position in the indoor environment for the detection of the room acoustic parameters.
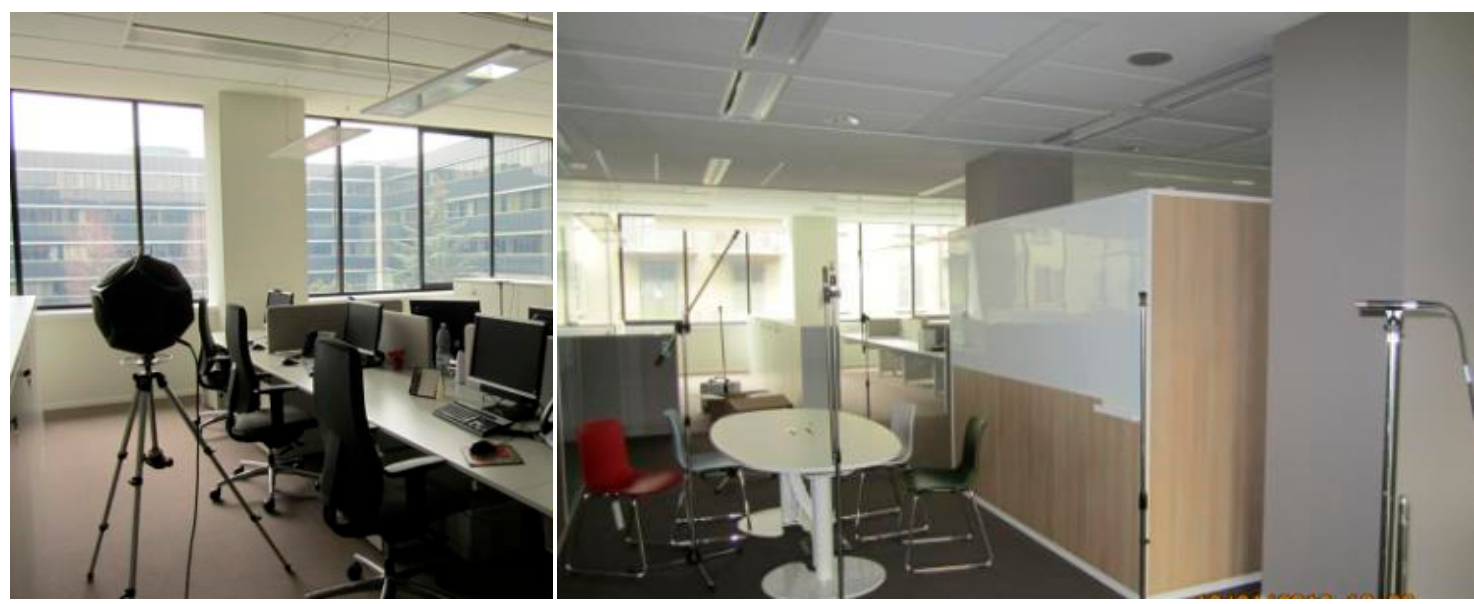

Figure 5. Omnidirectional sound source (left) and microphones (right) used for the measurement of the room acoustic parameters.

Table 9 shows the technical characteristics of the acoustic sensors.

Table 9. Technical features of the sensors for the measuring of acoustic parameters.

\begin{tabular}{ccc}
\hline Quantity & Sensor & Technical Characteristics \\
\hline Sound pressure level & Microphone & Measuring range $3.15 \mathrm{~Hz}-20 \mathrm{kHz}$ \\
& & Sensitivity $50 \mathrm{mV} / \mathrm{Pa}$ \\
\hline
\end{tabular}


Finally, a punctual survey was carried out in order to assess the level of exposure of workers to industrial frequency magnetic fields $(50 \mathrm{~Hz})$ and radio frequency electromagnetic fields and microwaves. A magnetic field meter was used to measure the magnetic induction value; an electromagnetic field meter equipped with an electric field probe was used to measure the electric field value. Technical characteristics are shown in Table 10.

Table 10. Features of the sensors for the measuring of lighting variables.

\begin{tabular}{ccc}
\hline Variable & Sensor & Technical Characteristics \\
\hline \multirow{2}{*}{ Magnetic Field } & Magnetic Field & Measuring range 0.1 to $700 \mathrm{mG}$ \\
& Measurement System & Accuracy $2-4 \%$ \\
Electromagnetic field & Electromagnetic field & Measuring range 0.35 to $450 \mathrm{~V} / \mathrm{m}$ \\
& measurement sensors & Accuracy n.a. \\
\hline
\end{tabular}

\section{Results}

This chapter illustrates the results of the monitoring campaign of the indoor environmental conditions and the application of the assessment tool to the case study. Table 11 shows the values of each indicator determined from the data collected during the monitoring campaign and the algorithms required by the technical standards and the minimum performance benchmarks. The data represent the average values calculated as a function of the survey period.

Table 11. Results for each environmental indicator.

\begin{tabular}{|c|c|c|c|c|c|}
\hline Criteria & Indicator & Winter Weeks & Summer Weeks & Punctual Surveys & Benchmark \\
\hline 1.1 & $\Delta \mathrm{CO}_{2}$ & - & - & $158 \mathrm{ppm}$ & $\Delta \mathrm{CO}_{2}<800 \mathrm{ppm}$ \\
\hline 2.1 & $\mathrm{PMV}_{\mathrm{W}}$ & 0.3 & - & - & $-0.7<\mathrm{PMV}<0.7$ \\
\hline 2.2 & $\mathrm{PMV}_{\mathrm{s}}$ & - & 0.4 & - & $-0.7<\mathrm{PMV}<0.7$ \\
\hline 2.3 & PD & 0.96 & 0.42 & - & $\mathrm{PD}<10 \%$ \\
\hline 2.4 & DR & 4.17 & 13.25 & - & $\mathrm{DR}<30$ \\
\hline 3.1 & DF & - & - & $2.61 \%$ & $\mathrm{DF}>2 \%$ \\
\hline 3.2 & $\mathrm{U}_{0, \text { surr }}$ & - & - & 0.91 & $\mathrm{U}>0.4$ \\
\hline 3.3 & $\mathrm{U}_{0, \text { back }}$ & - & - & 0.67 & $\mathrm{U}>0.1$ \\
\hline 3.4 & $\mathrm{R}_{\text {surr }}$ & - & - & 3.36 & $\mathrm{R}_{\text {surr }}<3$ \\
\hline 3.5 & $\mathrm{R}_{\text {back }}$ & - & - & 6.2 & $\mathrm{R}_{\text {back }}<10$ \\
\hline 3.6 & UGR & - & - & 2.9 & UGR $<19$ \\
\hline 4.1 & $\mathrm{~L}_{\mathrm{i}, \mathrm{w}}$ & - & - & $30.3 \mathrm{~dB}(\mathrm{~A})$ & $\mathrm{L}_{\mathrm{i}, \mathrm{w}}<45$ \\
\hline 4.2 & $\mathrm{~L}_{\mathrm{i}, \mathrm{s}}$ & - & - & $39.3 \mathrm{~dB}(\mathrm{~A})$ & $\mathrm{L}_{\mathrm{i}, \mathrm{s}}<45$ \\
\hline 4.3 & $\mathrm{~T}$ & - & - & $0.7 \mathrm{~s}$ & $\mathrm{~T}<0.8$ \\
\hline 4.4 & STI & - & - & 0.47 & $\mathrm{STI}<0.5$ \\
\hline 5.1 & B & - & - & $0.01 \mu \mathrm{T}$ & $\mathrm{B}<10 \mu \mathrm{T}$ \\
\hline 5.2 & E & - & - & $0.74 \mathrm{~V} / \mathrm{m}$ & $\mathrm{E}<20 \mathrm{~V} / \mathrm{m}$ \\
\hline
\end{tabular}

The values obtained show that almost all the indicators comply with the minimum requirements laid down by law. The behavior of the building related to some criteria is extremely positive; indeed, the values of some indicators exceed the mentioned limits, especially for critical positions of the indoor spaces.

The values related to indoor air quality are extremely positive with a very low $\mathrm{CO}_{2}$ concentration in accordance with Category I as laid down in EN 15251. 
Thermal comfort varies with the location of the measuring station. In winter the values of $\mathrm{PMV}_{\mathrm{W}}$ averaged over the survey period comply with class B of ISO EN 7730 ( -0.5 to +0.5$)$. In summer, low air temperatures and high air velocities are detected in some areas, resulting in higher $\mathrm{PMV}_{\mathrm{s}}$ than the predicted limit at certain times of the day. However, the average value is within the expected performance limits. The assessment of the local thermo-hygrometric conditions shows an excellent vertical distribution of temperature $(\mathrm{PD}<10 \%)$ and a reduced risk of draught, especially in winter. In summer, the high air velocity detected in the previous zones, causes a value of the DR index exceeding the value detected in winter, although lower than the required limit (DR $<30 \%)$.

The assessment of visual comfort was carried out both under natural and artificial lighting conditions. The assessment under natural conditions shows that the lighting requirements ensuring the smooth running of the work are not fully met: indeed, the collected data provide maintained illuminance to be less than the 500 lux according to the technical standard EN 12464-1:2011. The artificial lighting system is constantly in operation during working hours in order to counterbalance this limitation. In general, the survey showed an acceptable visual comfort. The daylight factor (DF) for most workstations is greater than $2 \%$. In two workstations the DF values are less than $2 \%$, due to the exposure to the north and the presence of external obstructions. The illuminance both in the task area and in the surrounding is more uniform as compared to the respective minimum values $\left(\mathrm{U}_{\text {surr }}>0.4, \mathrm{U}_{\text {back }}>0.1\right)$. The indicator $\mathrm{R}_{\text {surr }}$, determined for specific workstations, has values on average higher than the expected limit (1/3-3), thus indicating the possibility of visual discomfort in the performance of work, due to visual fatigue caused by constant changes in ocular adaptation. The same applies to the indicator $R_{\text {back }}$, albeit with minor effects. This discomfort is however reduced during working hours by switching on the lighting system. Under these conditions, in fact, there is no risk of glare from artificial light (UGR $<19)$ in any of the analysed positions.

As far as acoustic quality is concerned, there are no critical issues related to the noise of the system in operating conditions during winter $\left(\mathrm{L}_{\mathrm{i}, \mathrm{w}}<45 \mathrm{~dB}(\mathrm{~A})\right)$. In summer, this value exceeds the limits in one of the two monitored areas. The result of the monitoring of the reverberation time shows rather high values of the $\mathrm{T}$ index (low sound absorption condition), above the limits set by the regulations but still within an acceptable condition $(\mathrm{T}<0.8)$. The value of the STI index, close to the required limits, confirms this condition.

The levels of magnetic induction and electric field level detected in the indoor environment are lower than the respective quality values imposed by the reference limits at all measuring points

$$
(\mathrm{B}<3 \mu \mathrm{T}, \mathrm{E}<20 \mathrm{~V} / \mathrm{m}) .
$$

This brief discussion on the results from the monitoring campaign shows in general a good behavior of the building from the point of view of the IEQ. Some critical issues emerge in the evaluation of the thermal comfort of some limited areas during summer, in the evaluation of the visual comfort in natural light conditions and in the level of soundproofing. However, the found values obtained comply with minimum legal requirements.

These results made it possible to apply the assessment protocol aimed at quantifying the overall performance score of environmental quality. Figure 6 shows the scores obtained by each criterion and the overall IEQ score. 


\begin{tabular}{|l|}
\hline IEQ TOOL \\
\hline OFFICES \\
1. Air Quality \\
1.1 Air quality of indoor environments with mechanical ventilation \\
2.Thermal Comfort \\
2.1 Air temperature and air humidity in indoor environments with mechanical cooling \\
2.2 Air temperature and air humidity in indoor environments with mechanical heating \\
2.3 Vertical air temperature difference \\
2.4 Air velocity \\
3. Visual Comfort \\
3.1 Daylighting \\
3.2 Illuminance and Uniformity on the task area and on the immediate surrounding area \\
3.3 Illuminance and Uniformity on the task area and on background area \\
3.4 Daylighting discomfort glare in the immediate surrounding area \\
3.5 Daylighting discomfort glare on the background area \\
3.6 Discomfort glare due to artificial lighting \\
4. Acoustic Comfort \\
4.1 Noise from winter air-conditioning \\
4.2 Noise from summer air-conditioning \\
4.3 Sound reverberation in workplaces \\
4.4 Decrease in work performance \\
5. Electromagnetic pollution \\
5.1 Power frequency magnetic fields ( 50 Hertz) \\
5.2 Radio frequency and Microwave electromagnetic fields of indoor environment \\
\hline OVERALL IEQ SCORE \\
\hline
\end{tabular}

\begin{tabular}{|c|c|}
\hline Score & $\begin{array}{l}\text { Weighted } \\
\text { Score }\end{array}$ \\
\hline 5.0 & 1.0 \\
\hline 5.0 & 1.0 \\
\hline 3.5 & 1.3 \\
\hline 3.9 & 0.3 \\
\hline 3.1 & 0.2 \\
\hline 5.0 & 0.4 \\
\hline 5.0 & 0.4 \\
\hline 2.1 & 0.5 \\
\hline 3.1 & 0.2 \\
\hline 4.3 & 0.1 \\
\hline 1.7 & 0.1 \\
\hline-1.0 & 0.0 \\
\hline 2.1 & 0.0 \\
\hline 2.9 & 0.1 \\
\hline 1.4 & 0.5 \\
\hline 4.4 & 0.3 \\
\hline 1.7 & 0.1 \\
\hline 1.0 & 0.1 \\
\hline 0.3 & 0.0 \\
\hline 5.0 & 0.3 \\
\hline 5.0 & 0.1 \\
\hline 5.0 & 0.1 \\
\hline \multicolumn{2}{|c|}{3.5} \\
\hline
\end{tabular}

Figure 6. List of criteria and related scores (score and weighted score) and overall IEQ score.

\section{Discussion}

The improvement of the comfort levels within workplaces affects positively several fields with effects on well-being, productivity, energy efficiency and related economic benefits. However, these areas could conflict with each other. For example, energy efficiency of a building is affected positively by reduced ventilation rates, but for the well-being of the occupants, the ventilation rate should be higher in order to guarantee the minimum requirements for indoor air quality. Similarly, passive solutions such as natural ventilation and daylight improve users' satisfaction and productivity with a reduction of energy consumption and related costs. However, these solutions may not be enough to guarantee the minimum comfort levels and may require the application of active solutions with a consequent increase in costs [44]. This can be interpreted as a multi-objective optimization problem in which the objective function aims at maximizing users' well-being and productivity, increasing energy efficiency and reducing costs. Because of the complexity of this issue, indirect economic benefits should be taken into account. Better well-being conditions in the workplace result in an improvement of the workers' performance with consequent productivity benefits (economic value added produced by the worker). The economic value added along with the improvement of the energy efficiency compensates for the increased consumption to maintain the comfort conditions. The design process and the management of a building during the operational phase must take into account all these issues as to balance the weight of each aspect.

The integration of the IEQ tool in sustainable building systems based on the SB Method allows us to analyse the building in a wider perspective by including environmental, energy efficiency and economic issues in order to quantify its overall performance during the operational phase.

The IEQ tool was designed as to comply with the requirements of an office building. Emphasis was especially on the users' well-being in workplaces [45]. The scalability of the system will allow us to extend the evaluation to buildings with different intended uses, by applying specific assessment criteria. The IEQ tool described so far is among the sustainable tools available today. The main feature of the system is the quantitative approach that allows to provide a sound evaluation of the 
performance of the buildings. This approach partially differentiates the tool from other sustainable systems. The IEQ tool provides an in-depth and complete analysis of the internal comfort conditions of a building considering all the main issues according to one or more evaluation criteria. In particular, great attention is paid to the thermal comfort evaluated with four criteria, visual comfort with six criteria and acoustic quality with four criteria. The issue of electromagnetic pollution is also considered with the aim of minimizing the dangerous exposure of occupants to both power frequency magnetic fields and radio frequency and microwave electromagnetic fields.

Compared to the mostly used international assessment tools, the IEQ tool provides a quantitative assessment of the main issues related to the indoor comfort. Below the IEQ tool is briefly compared with two of the most well-known and used evaluation systems that can be applied to buildings during operational phase: "BREEAM in use" and "LEED O+M". The comparison is aimed at highlighting the strengths of the tool developed and described in this paper.

The "BREEAM in use" approach is prescriptive, i.e., each criterion calls for the implementation of technological solutions in order to acquire the credits assigned to the considered criterion [46]. This means that the tool describes the current state of the building at the time of the evaluation. The criteria indicate that measurements/verifications/controls of parameters should be carried out according to the legislation in force and that a qualified third party should perform them. However, they do not specify what parameters have to be assessed, how they should be measured or the performance to be achieved. The "BREEAM in use" tool addresses the issue of IEQ mainly within the Health and Well-being category. It focuses mainly on ventilation and air quality while thermal, visual and acoustic comfort are analysed with only one or two criteria. Electromagnetic pollution is not evaluated.

In general, also LEED O+M has a prescriptive approach, but some criteria indicate that measurements/verifications/controls of parameters should be made, indicating how to carry out the measurements and specifying the performance to be achieved [47]. In some cases, measuring and achieving performance is an alternative to implementing a technological solution. LEED O+M mainly deals with the issue of indoor air quality (IAQ) (five criteria, of which three mandatory prerequisites to be met) while thermal comfort is addressed by applying one criterion and visual comfort by applying two criteria. Acoustic comfort and electromagnetic pollution are not considered. Great importance is attached to green cleaning: according to the criteria, it must be verified that cleaning of the building is carried out with products, materials and equipment that do not compromise the quality of air and human health, the systems indoor surfaces and the environment.

The IEQ can be used as a support instrument due to the quantitative assessment offered by the SB Method. The tool allows to evaluate the design aspects that can be improved in a predefined layout and indirectly makes it possible to choose the most suitable technological solutions to achieve standard performance levels (legal minimums) or best performance levels (best practices).

\section{Conclusions}

The IEQ tool provides a performance assessment based on a measurement (i.e., quantitative and objective data) carried out by specific instruments in accordance with laws and technical regulations in force related to the specific issue.

Both LEED and BREEAM tools include criteria relating to occupants' satisfaction, through an anonymous survey (the former) and a procedure to collect feedback (the latter) that have to be carried out.

The developed tool allows us to verify the performance and functional layout of working spaces during the operational phase from the point of view of IEQ. The objective was to test the layout in order to replicate it on other floors (of the same building) and in other locations. The application of the IEQ tool, which also provided for the execution of a specific on-site monitoring, allowed us to identify possible areas of intervention to improve discomfort conditions that were manifested in a 
concrete manner through the results of the monitoring and especially through category scores and more specifically through the individual criteria scores obtained.

An ongoing research which may be further developed/described in future papers requires the preparation of questionnaires drawn up in collaboration with experts of adaptive and perceptive behavior in order to submit them to the occupants of the offices examined.

Author Contributions: Conceptualization, A.D. and L.B.; methodology, A.D., L.B. and F.S.; formal analysis, A.D., L.B. and F.S.; investigation, A.D., L.B., F.S.; data curation, A.D., L.B. and I.M.; writing — original draft preparation, A.D., L.B.; writing - review and editing, A.D., L.B and I.M.

Funding: This research received no external funding.

Acknowledgments: The authors would like to thank iiSBE International and the Italian chapter iiSBE Italia for their support to the research.

Conflicts of Interest: The authors declare no conflict of interest.

\section{References}

1. Brundtland, G. Chair of the World Commission on Environment and Development (WCED) Our Common Future, United Nations World Commission on Environment and Development. 1987. Available online: http:/ / www.un-documents.net/our-common-future.pdf (accessed on 17 February 2019).

2. Allouhi, A.; El Fouih, Y.; Kousksou, T.; Jamil, A.; Zeraouli, Y.; Mourad, Y. Energy consumption and efficiency in buildings: Current status and future trends. J. Clean. Prod. 2015, 109, 118-130. [CrossRef]

3. Cao, X.; Dai, X.; Liu, J. Building energy-consumption status worldwide and the state-of-the-art technologies for zero-energy buildings during the past decade. Energy Build. 2016, 128, 198-213. [CrossRef]

4. Kolokotsa, D.; Santamouris, M. Review of the indoor environmental quality and energy consumption studies for low income households in Europe. Sci. Total Environ. 2015, 536, 316-330. [CrossRef]

5. Esfandiari, M.; Zaid, S.M.; Ismail, M.A. Investigating the Indoor Environment Quality Parameters and Their Relationship with Occupants' Satisfaction in Office Buildings: A Review. J. Des. Built Environ. 2017, 17, 181-194.

6. Secchi, S.; Astolfi, A.; Calosso, G.; Casini, D.; Cellai, G.; Scamoni, F.; Scrosati, C.; Shtrepi, L. Effect of outdoor noise and façade sound insulation on indoor acoustic environment of Italian schools. Appl. Acoust. 2017, 126, 120-130. [CrossRef]

7. Piasecki, M.; Kozicki, M.; Firlag, S.; Goljan, A.; Kostyrko, K. The approach of including TVOCS concentration in the indoor environmental quality model (IEQ) - Case studies of BREEAM certified office buildings. Sustainability 2018, 10, 3902. [CrossRef]

8. Calama-González, C.M.; Suárez, R.; León-Rodríguez, Á.L.; Ferrari, S. Assessment of Indoor Environmental Quality for Retrofitting Classrooms with an Egg-Crate Shading Device in a Hot Climate. Sustainability 2019, 11, 1078. [CrossRef]

9. Vilcekova, S.; Meciarova, L.; Burdova, E.K.; Katunska, J.; Kosicanova, D.; Doroudiani, S. Indoor environmental quality of classrooms and occupants' comfort in a special education school in Slovak Republic. Build. Environ. 2017, 120, 29-40. [CrossRef]

10. Salamone, F.; Belussi, L.; Danza, L.; Ghellere, M.; Meroni, I. Integration of a do it yourself Hardware in a Lighting Device for the Management of Thermal Comfort and Energy Use. Energy Procedia 2016, 101, 161-168. [CrossRef]

11. Salamone, F.; Belussi, L.; Danza, L.; Ghellere, M.; Meroni, I. How to control the Indoor Environmental Quality through the use of the Do-It-Yourself approach and new pervasive technologies. Energy Procedia 2017, 140, 351-360. [CrossRef]

12. Casini, D.; Cellai, G.; Fogola, J.; Scamoni, F.; Secchi, S. Correlation between facade sound insulation and urban noise: A contribution to the acoustic classification of existing buildings. Build. Acoust. 2016, 23, 145-158. [CrossRef]

13. Mateus, R.; Bragança, L. Sustainability assessment and rating of buildings: Developing the methodology SBToolPT-H. Build. Environ. 2011, 46, 1962-1971. [CrossRef]

14. Alyami, S.H.; Rezgui, Y. Sustainable building assessment tool development approach. Sustain. Cities Soc. 2012, 5, 52-62. [CrossRef] 
15. Chew, M.Y.L.; Das, S. Building grading systems: A review of the state-of-the-art. Archit. Sci. Rev. 2008, 51, 3-13. [CrossRef]

16. Andrade, J.B.; Bragança, L. Sustainability assessment and standardization: Steel buildings. Concepts Methods Steel Intensive Build. Proj. 2012, 213-224.

17. Sev, A. A comparative analysis of building environmental assessment tools and suggestions for regional adaptations. Civil Eng. Environ. Syst. 2011, 28, 231-245. [CrossRef]

18. Mattoni, B.; Guattari, C.; Evangelisti, L.; Bisegna, F.; Gori, P.; Asdrubali, F. Critical review and methodological approach to evaluate the differences among international green building rating tools. Renew. Sustain. Energy Rev. 2018, 82, 950-960. [CrossRef]

19. Ghellere, M.; Devitofrancesco, A.; Meroni, I. Urban sustainability assessment of neighborhoods in Lombardy. Energy Procedia 2017, 122, 44-49. [CrossRef]

20. Devitofrancesco, A.; Ghellere, M.; Meroni, I.; Modica, M.; Paleari, S.; Zoboli, R. Sustainability assessment of urban areas through a multicriteria decision support system. In CESB 2016-Central Europe Towards Sustainable Building 2016: Innovations for Sustainable Future; Grada Publishing: Prague, Czech Republic, 2016; pp. 499-506.

21. Pons, O.; de la Fuente, A.; Aguado, A. The use of MIVES as a sustainability assessment MCDM method for architecture and civil engineering applications. Sustainability 2016, 8, 460. [CrossRef]

22. Alborz, N.; Berardi, U. A post occupancy evaluation framework for LEED certified US higher education residence halls. Procedia Eng. 2015, 118, 19-27. [CrossRef]

23. Shika, S.A.; Sapri, M.; Jibril, J.D.A.; Sipan, I.; Abdullah, S. Developing post occupancy evaluation sustainability assessment framework for retrofitting commercial office buildings: A proposal. Procedia Soc. Behav. Sci. 2012, 65, 644-649. [CrossRef]

24. Agha-Hossein, M.M.; El-Jouzi, S.; Elmualim, A.A.; Ellis, J.; Williams, M. Post-occupancy studies of an office environment: Energy performance and occupants' satisfaction. Build. Environ. 2013, 69, 121-130. [CrossRef]

25. Bonde, M.; Ramirez, J. A post-occupancy evaluation of a green rated and conventional on-campus residence hall. Int. J. Sustain. Built Environ. 2015, 4, 400-408. [CrossRef]

26. Kern, A.P.; Antoniolli, C.B.; Wander, P.R.; Mancio, M.; González, M.A.S. Energy and water consumption during the post-occupancy phase and the users' perception of a commercial building certified by Leadership in Energy and Environmental Design (LEED). J. Clean. Prod. 2016, 133, 826-834. [CrossRef]

27. Baird, G.; Field, C. Thermal comfort conditions in sustainable buildings-Results of a worldwide survey of users' perceptions. Renew. Energy 2013, 49, 44-47. [CrossRef]

28. Heinzerling, D.; Schiavon, S.; Webster, T.; Arens, E. Indoor environmental quality assessment models: A literature review and a proposed weighting and classification scheme. Build. Environ. 2013, 70, 210-222. [CrossRef]

29. Larsson, N. SB Method and SBTool for 2011. Overview. International Initiative for a Sustainable Built Environment. 2011. Available online: http:/ /iisbe.org/sbmethod-2010 (accessed on 17 February 2019).

30. Asdrubali, F.; Baldinelli, G.; Bianchi, F.; Sambuco, S. A comparison between environmental sustainability rating systems LEED and ITACA for residential buildings. Build. Environ. 2015, 86, 98-108. [CrossRef]

31. ITACA Protocols. Available online: http://itaca.org/valutazione_sostenibilita.asp (accessed on 17 February 2019).

32. Epstein, M.J.; Roy, M.J. Sustainability in action: Identifying and measuring the key performance drivers. Long Range Plan. 2001, 34, 585-604. [CrossRef]

33. European Committee for Standardization. CEN 15251:2007 Indoor Environmental input Parameters for Design and Assessment of Energy Performance of Buildings Addressing Indoor Air Quality, Thermal Environment, Lighting and Acoustics; European Committee for Standardization: Brussels, Belgium, 2007.

34. European Committee for Standardization. CEN 13779:2007. Ventilation for Non-Residential Buildings-Performance Requirements for Ventilation and Room-Conditioning Systems; European Committee for Standardization: Brussels, Belgium, 2007.

35. International Organization for Standardization. ISO 7730:2005. Ergonomics of the Thermal EnvironmentAnalytical Determination and Interpretation of Thermal Comfort Using Calculation of the PMV and PPD Indices and Local Thermal Comfort Criteria; International Organization for Standardization: Geneva, Switzerland, 2005.

36. European Committee for Standardization. CEN 12464-1:2011. Light and Lighting —Lighting of Work Places-Part 1: Indoor Work Places; European Committee for Standardization: Brussels, Belgium, 2011. 
37. European Committee for Standardization. CEN 15193:2017. Energy Performance of Buildings-Energy Requirements for Lighting; European Committee for Standardization: Brussels, Belgium, 2017.

38. International Organization for Standardization. ISO 3382-2:2008. Acoustics-Measurements of Room Acoustics Parameters-Part, 2, Reverberation Time in Ordinary Rooms; International Organization for Standardization: Geneva, Switzerland, 2008.

39. International Organization for Standardization. ISO 3382-3:2012. Acoustics-Measurement of Room Acoustic Parameters_Part, 3, Open Plan Offices; International Organization for Standardization: Geneva, Switzerland, 2012.

40. International Organization for Standardization. ISO 9921:2003. Ergonomics-Assessment of Speech Communication; International Organization for Standardization: Geneva, Switzerland, 2003.

41. International Electrotechnical Commission. IEC 60268-16:2011. Sound System Equipment_Part 16: Objective Rating of Speech Intelligibility by Speech Transmission Index; International Electrotechnical Commission: Geneva, Switzerland, 2011.

42. Legislative Decree 9 april 2008, n. 81. 2008 Attuazione dell'articolo 1 della legge 3 agosto 2007, n.123, in materia di tutela della salute e della sicurezza nei luoghi di lavoro-Allegato XXXVI “Valori limite di esposizione e valori di azione per i campi elettromagnetici". Available online: http:/ /www.lavoro.gov.it (accessed on 19 March 2019).

43. De Gennaro, G.; Dambruoso, P.R.; Loiotile, A.D.; Di Gilio, A.; Giungato, P.; Tutino, M.; Marzocca, A.; Mazzone, A.; Palmisani, J.; Porcelli, F. Indoor air quality in schools. Environ. Chem. Lett. 2014, 12, 467-482. [CrossRef]

44. Fisk, W.J.; Black, D.; Brunner, G. Benefits and costs of improved IEQ in US offices. Indoor Air 2011, 21, 357-367. [CrossRef]

45. Al-horr, Y.; Arif, M.; Katafygiotou, M.; Mazroei, A.; Kaushik, A.; Elsarrag, E. Impact of indoor environmental quality on occupant well-being and comfort: A review of the literature. Int. J. Sustain. Built Environ. 2016, 5, 1-11. [CrossRef]

46. BREEAM In-Use International: Technical Manual. 2016. Available online: https://tools.breeam.com (accessed on 2 February 2019).

47. LEED v4.1 Operations and Maintenance. 2018. Available online: https://www.usgbc.org (accessed on 15 February 2019).

(C) 2019 by the authors. Licensee MDPI, Basel, Switzerland. This article is an open access article distributed under the terms and conditions of the Creative Commons Attribution (CC BY) license (http:// creativecommons.org/licenses/by/4.0/). 